\title{
Resilience and Coping as Moderators of Stress-Related Growth in Asians and AAPIs During COVID-19
}

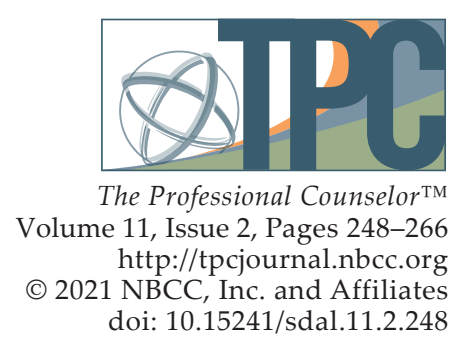

\author{
Stacey Diane Arañez Litam, Seungbin Oh, Catherine Chang
}

This exploratory study examined the extent to which coping, resilience, experiences of subtle and blatant racism, and ethnic identity predicted stress-related growth in a national convenience sample of Asians and Asian Americans and Pacific Islanders (AAPIs; $N=326$ ) who experienced COVID-19-related racial discrimination. Our analysis indicated participants with higher levels of coping, resilience, experiences of subtle and blatant racism, and ethnic identity were significantly more likely to cultivate higher levels of stress-related growth. Coping strategies such as self-blame, religion, humor, venting, substance use, denial, and behavioral disengagement significantly moderated the relationship between experiences of racism and stress-related growth. Notably, participants in the study who used mental health services following COVID-19 reported significantly higher levels of racial discrimination, resilience, coping, and stress-related growth compared to Asians and AAPIs who did not use professional mental health services. Mental health professionals are called to utilize culturally sensitive treatment modalities and challenge traditional Western notions that frame coping responses from an individualistic worldview.

Keywords: Asian, Asian American, COVID-19, racial discrimination, stress-related growth

Asians and Asian Americans and Pacific Islanders (AAPIs) represent vulnerable ethnic groups that may present with higher rates of mental health distress during COVID-19. Following the global outbreak, rates of discrimination, harassment, and violence toward Asians and AAPIs have substantially increased (Congressional Asian Pacific American Caucus, 2020; Jeung \& Nham, 2020). The rise of COVID-19-fueled racism directed toward Asians and AAPI groups, especially individuals who phenotypically appear East Asian, has deleterious effects on their mental health and wellness (Litam, 2020; Litam \& Oh, in press, 2020; Wen et al., 2020).

Although Asians who reside in the United States and AAPI groups are both affected by COVID-19related racial discrimination, mental health professionals must recognize the important distinctions and challenges that exist between Asian internationals and Asian Americans (Anandavalli et al., 2020; Sue et al., 2019). Professional counselors must also consider the vast heterogeneity that characterizes Asian and AAPI ethnic subgroups (Budiman \& Ruiz, 2021; Chan \& Litam, 2021). Although an extensive overview of the differences between Asians and AAPI ethnic subgroups was beyond the purview of this study, mental health professionals are called to examine how the intersection of client identities (e.g., international status, nationality, ethnic identity, acculturative status, colonization history) may influence the ways in which COVID-19 racial discrimination affects Asian and AAPI clients (Chan \& Litam, 2021; Litam, 2020). For the purpose of contributing to the scant literature on the effects of COVID-19 on Asian and AAPI communities, the current study assesses a national convenience sample of Asians and AAPI groups who reported discrimination experiences following the pandemic. Aggregating these distinct populations was not intended to overlook the vast heterogeneity that exists across ethnic subgroups nor to invalidate

Stacey Diane Arañez Litam, PhD, NCC, CCMHC, LPCC-S, is an assistant professor at Cleveland State University. Seungbin Oh, PhD, NCC, LPC, is an assistant professor at Merrimack College. Catherine Chang, PhD, NCC, LPC, CPCS, is a professor at Georgia State University. Correspondence may be addressed to Stacey Litam, 2121 Euclid Ave., Cleveland, OH 44115, s.litam@csuohio.edu. 
the unique challenges faced by Asian and AAPI individuals who reside in the United States. Rather, the present study combined Asian and AAPI populations to ascertain a more collective understanding of the ways in which the greater community may be affected by COVID-19-related racial discrimination.

\section{Effects of Racial Discrimination on Asian and AAPI Mental Health}

Extant research illuminated how perceived racial discrimination among Asian and AAPI communities has adverse effects on overall mental health, coping responses, and wellness. Asians and AAPIs who faced race-based discrimination reported higher levels of psychological distress, substance use, anxiety, depression, and suicidal ideation (Choi et al., 2020; Gee et al., 2007; Hwang \& Goto, 2008; Le \& Ahn, 2011; Leong et al., 2013). Experiences of race-related stress in Asians and AAPIs were also associated with negative outcomes related to well-being (Iwamoto \& Liu, 2010; Mossakowski, 2003), self-esteem (Liang \& Fassinger, 2008), and social connectedness (Wei et al., 2012). Although the importance of understanding the effects of COVID-19-related racial discrimination on the mental health of Asians and AAPIs has been established (Asmundson \& Taylor, 2020; Chan \& Litam, 2021; Litam, 2020), a paucity of empirical investigations examines the mental health effects of pandemic-related discrimination among Asians and AAPIs across the life span (Litam \& Oh, in press).

\section{Ethnic Identity}

Ethnic identity is the quality of an individual's affiliation with their ethnic group and includes a sense of belongingness, self-identification, and attitudes toward one's group (Phinney, 1990). Phinney (1992) outlined four developmental stages based on high and low levels of exploration and commitment. Whereas exploration includes activities and behaviors undertaken to understand the role of one's ethnicity or race in one's identity, commitment refers to the affirmation, sense of connection, and clarity about how one's ethnic or racial identity fits into one's life and self-concept (Phinney, 1992). Taken together, the two dimensions of exploration and commitment form four statuses of ethnic and/or racial identity development: diffused (low exploration, low commitment), foreclosed (low exploration, high commitment), moratorium (high exploration, low commitment), and achieved (high exploration, high commitment; Erikson, 1968).

The mixed effect of ethnic identity in the relationship between racial discrimination experiences and well-being has been noted across earlier studies. On one hand, existing research has noted that Asians and AAPIs who cultivated strong ethnic identities were more likely to maintain a positive sense of psychological well-being, reported a greater sense of belongingness to their ethnic communities, and responded with greater resilience when racial discrimination occurred (Lee, 2003; Lee \& Davis, 2000; Lee \& Yoo, 2004; Litam \& Oh, in press; Phinney, 2003; Yip \& Fuligni, 2002). In the United States, AAPIs with a strong sense of ethnic identity reported a better quality of life and greater levels of spousal support and harmony (Lieber et al., 2001). In one study with 187 Chinese and Chinese Americans, strong ethnic identity moderated the relationship between experiences of COVID-19 discrimination and levels of depression (Litam \& Oh, 2020). Levels of exploration and commitment may additionally influence whether ethnic identity buffers or exacerbates well-being among Asians and AAPIs who experience racial discrimination. According to a meta-analysis of 51 studies, Yip and colleagues (2019) asserted that individuals high in exploration reported more negative mental health and riskier health behavior outcomes following experiences of racial discrimination. Conversely, ethnic identity was a protective factor for individuals with high levels of commitment following racial discrimination (Yip et al., 2019).

The moderating effects of ethnic identity on Asian and AAPI mental health may be framed within the context of social identity theory (Tajfel \& Turner, 1979) and self-categorization theory (Turner et al., 1987). According to social identity theory (Tajfel \& Turner, 1979), individuals are members of many social 
groups with whom they may identify (e.g., religion, race, ethnicity, gender). Once individuals have determined their social identities, they become invested in maintaining and enhancing their self-concept (Tajfel \& Turner, 1979). Social identity theory therefore predicts that individuals who center their identities are better equipped to cope with identity threats to protect their overall self-concept (Tajfel \& Turner, 1979). Through the lens of this theory, individuals who strongly identify with their Asian or AAPI identities may be better positioned to engage in coping strategies that buffer the harmful impact of ethnic or racial discrimination.

Self-categorization theory builds on social identity theory by recognizing that individuals can identify with several social groups simultaneously and that some social identities become more psychologically salient than others (Turner et al., 1987). When ethnic identity becomes salient and represents an important component of one's identity, self-categorization theory predicts that ethnic and racial discrimination will have a stronger negative impact on mental health and wellness outcomes (Turner et al., 1987). Taken together, social categorization theory predicts that positive feelings toward one's ethnic group may heighten awareness to ethnic discrimination, which may exacerbate the harmful effects of ethnic or racial discrimination (Lee, 2005), whereas social identity theory posits that high regard for one's ethnic identity may result in a buffering effect to the deleterious effects of racial discrimination (Yip et al., 2019).

\section{Resilience}

Resilience refers to the "personal qualities that enable one to thrive in the face of adversity" (Connor \& Davidson, 2003, p. 76). Although responding with resilience in times of stress has been reported across diverse AAPI subgroups, various ethnic groups may conceptualize resilience in unique ways. As a coping strategy, resilience is not limited to how one responds to challenges but also encompasses strategies for goal achievement. For example, Hmong women demonstrated resilience in career development by adopting positive perspectives, focusing on goal achievement, and reflecting on ways to continue improving (Yang, 2014). In another study, Chinese immigrants demonstrated fortitude through the immigration process and continued to thrive in the United States despite living in poverty in a California Chinatown community (Cheng, 2013). Resilience, therefore, consists of a stress response and an enduring phenomenon. Resilience may be fostered through the presence of social support, especially among family members (Lim \& Ashing-Giwa, 2013), through the promotion of cultural understanding (i.e., cultivating ethnic identity), engaging in meaningful activities, and developing mental toughness (i.e., resilience; Kim \& Kim, 2013).

\section{Coping and Stress Responses}

Individuals evaluate racial discrimination experiences and cope with stressors differently based on their cultural values and beliefs (Lazarus \& Folkman, 1984; Tweed \& Conway, 2006). Asians and AAPIs who endorse higher levels of ethnic identity may be more likely to employ coping strategies that align with culturally embedded values (Miller \& Kaiser, 2001; Miller \& Major, 2000). These cultural values may assert the importance of adjusting one's feelings to fit their environment, accepting rather than confronting problems, preserving social harmony, avoiding problem disclosure (Inman \& Yeh, 2007; Tweed \& Conway, 2006; Yeh et al., 2006), and evading conflict to preserve interpersonal relationships (Noh \& Kaspar, 2003). These passive forms of coping may be problematic, as avoidant and emotionfocused responses may contribute to poorer mental health outcomes in AAPIs.

Other culturally congruent coping responses such as social isolation, which protects the user by avoiding the stressor (Edwards \& Romero, 2008); self-blame or criticizing oneself, which maintains interpersonal harmony (Wei et al., 2010); and substance use (Pokhrel \& Herzog, 2014), which momentarily helps one evade problems or adjust one's feelings to the environment, may also be 
preferred by Asians and AAPIs. Following stressful events, social isolation has been strongly linked to increased symptoms of depression and anxiety, decreased feelings of self-worth, and lower levels of life satisfaction (Cacioppo \& Hawkley, 2003; Cacioppo et al., 2002).

\section{Stress-Related Growth}

Individuals may respond to stressful life events, transitions, and traumatic experiences with positive psychological changes (Park et al., 1996; Tedeschi \& Calhoun, 2004). Researchers posit that coping strategies (Helgeson et al., 2006; Janoff-Bulman, 2004; Tedeschi \& Calhoun, 2004), higher levels of selfesteem, positive spiritual changes, and increased social support (Linley \& Joseph, 2004; Tedeschi \& Calhoun, 1995, 2004) may arise following experiences of stress. According to Tedeschi and Calhoun $(1996,2004)$, examples of stress-related growth may include pursuing new possibilities, having a greater appreciation for life, cultivating meaningful relationships, enhancing spiritual growth, and developing personal strengths. A meta-analysis of 103 studies identified the presence of coping strategies, cognitive reappraisal, religion, optimism, and social support as significant predictors for stress-related growth (Prati \& Pietrantoni, 2009). A qualitative study with Korean immigrants indicated the use of coping strategies was a predictor for stress-related growth (Kim \& Kim, 2013).

Tedeschi and Calhoun $(1996,2004)$ conceptualized stress-related growth as both a long-term outcome and a process. For instance, stress-related growth has been conceptualized as a coping strategy following traumatic events (Nolen-Hoeksema \& Davis, 2004) and may occur as the result of ongoing medical conditions such as cancer (Cordova et al., 2017) and chronic pain (Rzeszutek \& Gruszczyńska, 2018), wherein traumatic experiences are not time-limited. Thus, stress-related growth may result from the ongoing process of awareness, adaptation, and concern related to medical, psychological, and social consequences associated with the conditions of living (Edmondson et al., 2011). Given the precedence of emerging research that measures stress-related growth during COVID-19 (Vasquez et al., 2021), stress-related growth was included as an outcome variable in our study. This variable was of particular interest because research remains forthcoming on the contributing factors to stress-related growth among Asians and AAPIs following experiences of stress related to COVID-19.

The call to identify moderators of mental health in Asian and AAPI communities following racial discrimination has been established (Litam, 2020; Litam \& Oh, in press; Nadal et al., 2015; Wong et al., 2014). It is of paramount importance to identify race-related response strategies to develop culturally sensitive and effective counseling interventions (Chan \& Litam, 2021; Frazier et al., 2004; Litam \& Hipolito-Delgado, 2021). The relationship between COVID-19-fueled racial discrimination, ethnic identity, resilience, and coping responses in Asian and AAPI populations remains to be seen and necessitates special consideration for mental health professionals. Understanding this relationship is crucial when considering how Asians and AAPIs tend to avoid health care services (DeVitre \& Pan, 2020; Sue et al., 2019). To address this paucity of literature, this study was undertaken to examine the following research questions:

1. To what extent do coping, resilience, experience of racism, and ethnic identity predict stressrelated growth following COVID-19?

2. To what extent does coping moderate experiences of COVID-19-related racism and stressrelated growth?

3. To what extent does resilience moderate experiences of COVID-19-related racism and stressrelated growth? 


\section{Method}

\section{Participants}

Data was collected from June to July 2020. A total of 409 Asian and AAPI individuals were recruited through AAPI listservs and community organizations $(n=10)$ and Amazon MTurk $(n=399)$. Sixty-eight respondents from Amazon MTurk completed less than $50 \%$ of the survey items, so their associated surveys were removed from the data. An additional 11 respondents from Amazon MTurk endorsed all survey items with the same response or incorrectly answered validity items, and their surveys were also eliminated from the data. Lastly, four multivariate outliers were removed (i.e., Mahalanobis distance value $>20.515$ at $\alpha=.001)$, resulting in a final sample of 326 cases (79.7\% useable response rate). The final sample $(N=326)$ met sufficient sample size for hierarchical multiple regression $(N>94)$ and a path analysis $\left(N>134\right.$; $\mathrm{O}^{\prime}$ Rourke \& Hatcher, 2013) at $\alpha=.01$ to identify medium effect size.

\section{Table 1}

\section{Descriptive Characteristics and Correlations}

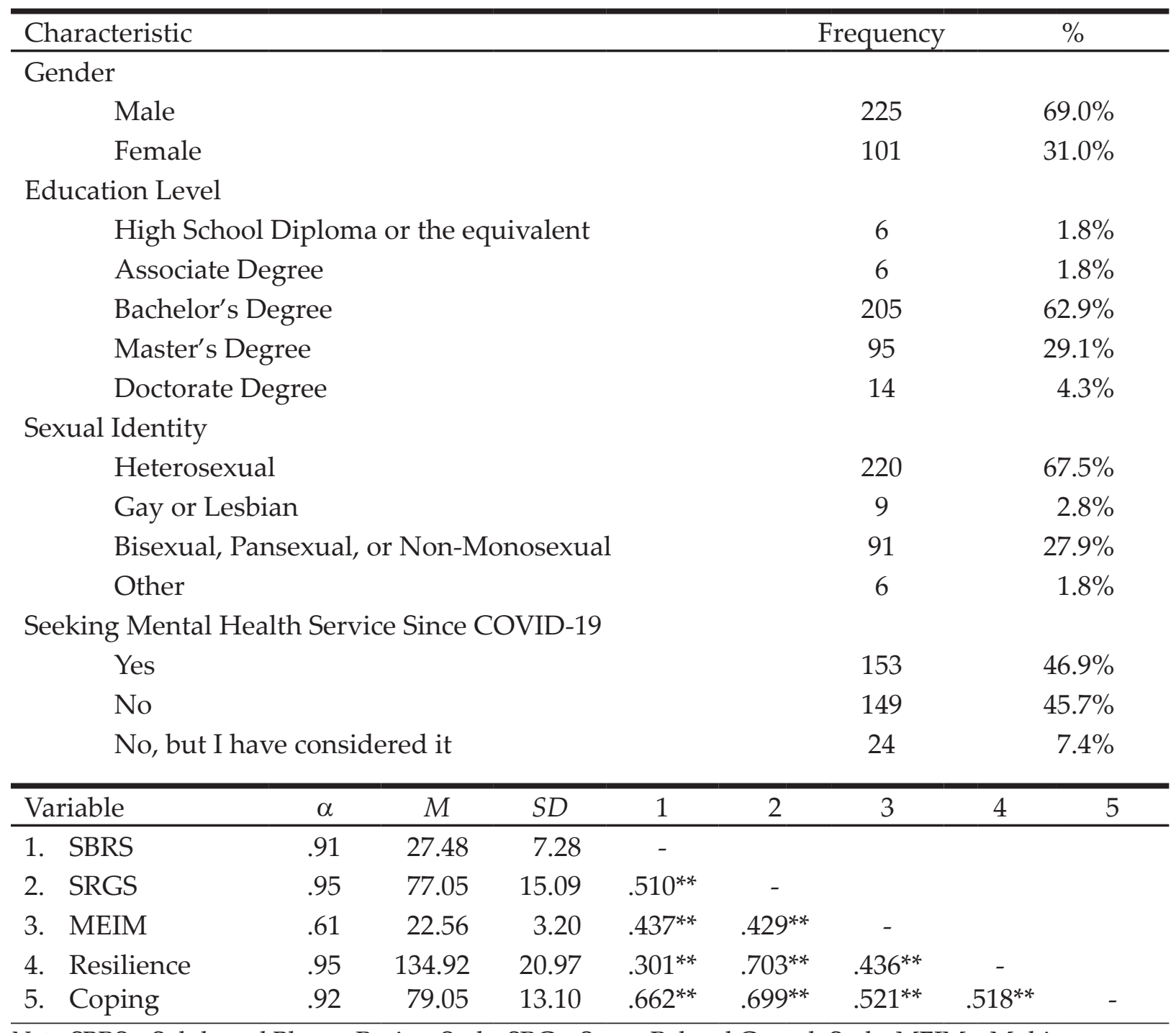

Note. SBRS = Subtle and Blatant Racism Scale; SRG = Stress-Related Growth Scale; MEIM = Multigroup Ethnic Identity Measure.

${ }^{* *} p<.01$ 
Table 1 presents details regarding descriptive characteristics of participants in this study. The average age of Asian and AAPI participants was 33.79 years $(S D=9.19)$, ranging from 18 to 72 years. The majority of participants identified as male $(69.0 \%, n=225)$, and a smaller group identified as female $(31 \% ; n=101)$. Most participants reported having an international status $(72.7 \%, n=237)$, whereas $27.3 \%$ of participants $(n=89)$ identified as an American citizen or permanent U.S. resident. For one item, "Have you sought professional mental health counseling services since COVID-19?" approximately half of the participants $(46.9 \%, n=153)$ selected "Yes," a total of 150 participants (45.7\%) selected "No," and a total of 24 participants $(7.4 \%)$ indicated "No, but I've considered it."

\section{Procedures}

IRB approval from relevant universities was obtained prior to data collection. Potential participants were recruited using non-probability convenience sampling with inclusion criteria. Participants who (a) self-identified as Asian or Asian American, (b) resided in the United States, and (c) had either directly or indirectly experienced COVID-19-related racism were able to participate in the study. Participants from the MTurk obtained $\$ 0.50$ as an incentive for their completion of the survey. To ensure the quality of data, the survey included two validity items that asked participants to choose specific response options. Participants who chose incorrect responses were automatically excluded from participation in the survey.

\section{Measures}

\section{Demographics and Background Form}

A demographics/background information form was created to gather information regarding participants' age, gender, highest level of education, race/ethnicity, sexual identity, income level, occupation, international status, religion, and generational status. Additional survey items assessed English proficiency and how rates of discrimination evidenced through verbal, covert, online, and physical harassment may have changed following COVID-19. Participants were provided with the option to input text describing additional forms of racial discrimination experienced since COVID-19.

\section{Multigroup Ethnic Identity Measure - Revised (MEIM-R)}

The Multigroup Ethnic Identity Measure (MEIM; Phinney, 1992) is a 14-item scale that assesses three aspects of ethnic identity: positive ethnic attitudes and a sense of belonging (five items), ethnic identity achievement (seven items), and ethnic behaviors or practices (two items). The measure is scored by reversing negatively worded items, summing the scores across each item, and obtaining the mean. Scores range from 4 (high ethnic identity) to 1 (low ethnic identity). Overall reliability was .90 in a college sample, and the results of a principal axis factor analysis using squared multiple correlations supported the presence of two factors, ethnic identity and other-group group orientation, accounting for $30.8 \%$ and $11.4 \%$ in college samples, respectively (Phinney, 1992). The MEIM was shortened into a six-item scale that measures two subscales, Identity Exploration and Identity Commitment (MEIM-R; Brown et al., 2014). Example items include "I have spent time trying to find out more about my own ethnic group, such as its history, traditions, and customs" and "I think a lot about how my life will be affected by my ethnic group membership." The MEIM-R demonstrated adequate internal consistency for the overall scale and two subscales with all Cronbach alpha values near or above .70 (Brown et al., 2014). Based on the results of multiple-groups confirmatory factor analyses, the MEIM-R demonstrated evidence of measurement invariance, had good psychometric properties, and is an appropriate measure of ethnic identity across diverse Asian subgroups (Brown et al., 2014).

\section{Resilience Scale (RS)}

The Resilience Scale (RS; Wagnild \& Young, 1993) is a 25-item measure that uses a 7-point Likerttype scale from 1 (strongly disagree) to 7 (strongly agree). Example items include "I usually manage one 
way or another" and "I feel that I can handle many things at a time." The RS demonstrated a coefficient alpha of .91 with item-to-total correlations ranging from .37 to .75 . The concurrent validity of the RS was also robust and was strongly associated with measures of life satisfaction, morale, and depression. The results of a factor analysis indicated the RS is a reliable measure that demonstrated good internal consistency reliability, concurrent validity, and preliminary construct validity (Wagnild \& Young, 1993).

\section{Subtle and Blatant Racism Scale for Asian Americans Revised (SABRA-A $)$}

The Subtle and Blatant Racism Scale for Asian Americans Revised (SABRA-A²; Yoo et al., 2010) is an 8-item measure that uses a 5-point Likert-type scale from 1 (almost never) to 5 (almost always) to assess the presence of subtle and blatant forms of racial discrimination. The total score is obtained by summing the responses across each of the items, with higher scores indicating greater perceived racism. Example items include "In America, I am faced with barriers in society because I'm Asian" and "In America, I have been physically assaulted because I'm Asian." Support for the two-subscale structure was confirmed through an exploratory and confirmatory factor analysis with evidence of good internal reliability and stability over 2 weeks (Yoo et al., 2010). The SABRA-A ${ }^{2}$ also demonstrated good discriminant validity as evidenced by no correlations with color-blind racial attitudes (Yoo et al., 2010).

\section{Brief COPE}

The Brief COPE (Carver, 1997) is a 28-item measure and uses a 4-item Likert-type scale to measure the extent to which participants report using various coping strategies. The measurement has 14 subscales that include two items each. Available responses are 1 (I haven't been doing this at all), 2 (I've been doing this a little bit), 3 (I've been doing this a medium amount), and 4 (I've been doing this a lot). Example items include "I've been concentrating my efforts on doing something about the situation I'm in" and "I've been criticizing myself." The Brief COPE has demonstrated acceptable psychometric properties and has been used with Asian populations (Sue et al., 2019). Cronbach's alpha for the entire scale is .92 in the current study. Cronbach's alpha for each of the 14 subscales ranged from .34 to .65. Given the poor reliability for the subscales, the present study utilized the total score for the entire scale.

\section{Stress-Related Growth Scale Revised (SRGS-R)}

The Stress-Related Growth Scale Revised (SRGS-R; Boals \& Schuler, 2018), is a 15-item measure that assesses the extent to which participants experience change following a negative event. The scale uses a bipolar 7-point Likert-type scale from -3 (a very negative change) to +3 (a very positive change), and example items include "I experienced a change in the extent to which I listen when others talk to me" and "I experienced a change in my belief that I have something of value to teach others about life." The SRGS-R demonstrated acceptable measures of convergent validity and stronger associations with outcome measures of mental health, including depression, anxiety, global distress, and post-traumatic symptoms (Boals \& Schuler, 2018). Compared to other measures, the SRGS-R may be a more accurate measure for human resiliency as evidenced by the neutral wording of each item and the inclusion of items that avoid measuring illusory growth (Boals \& Schuler, 2018).

\section{Data Diagnostics}

Examining the proportion of missing data indicated that $88 \%$ of participants reported no missing values, and $83 \%$ of the items were not missing data for any case. The proportion of missing data for the rest of the $17 \%$ of the items ranged from $2.7 \%$ to $16.8 \%$. The degree and pattern of missing data were examined to determine whether data were missing at random. A matrix of the estimated means with each pattern yielded no particular patterns nor severe degree of missing data, which supported evidence for proceeding with missing data replacement techniques. Missing data points were populated using 
multiple imputation (MI), a method to allocate missing data without causing inflated bias even when there is a large portion of missingness in the data (Osborn, 2013).

Next, the assumptions of normality, linearity, homoscedasticity, and multicollinearity were tested. The residuals were linear and did not deviate from normality as evidenced by the residuals lying reasonably in a straight, diagonal line. The assumption of homoscedasticity was also supported, as most of the residuals were concentrated along the zero point. All variance inflation factor (VIF) values were less than 10 and tolerance values were greater than .1, indicating absence of multicollinearity (Tabachnick \& Fidell, 2019). Therefore, the data were deemed appropriate for hierarchical regression and path analysis (Tabachnick \& Fidell, 2019).

\section{Analytic Strategy}

Hierarchical regression models of stress-related growth were employed using SPSS version 27. First, gender, age, education status, sexual identity, and help-seeking experience were entered in Model 1 as the control variables. In Model 2, the first independent variable of subtle and blatant racism was added. In Model 3, the second independent variable of ethnic identity was entered. Finally, the remaining two independent variables of resilience and coping strategy were added as key predictors that may function as potential moderators in Model 4.

To examine potential moderating roles of resilience and coping strategy in the relationship between racism and stress-related growth, Hayes' (2018) PROCESS macro version 3.5 was conducted. Specifically, 10,000 bootstrapping resampling was conducted to produce $95 \%$ percentile confidence intervals (CIs) for the moderating effect. If the CIs excluded zero, moderating effect was considered to be significant. Furthermore, the moderating effects were examined utilizing three conditional values of moderators (Hayes, 2018; Preacher et al., 2017), which included low (the mean score of the moderator -1 SD), moderate (the mean score), and high values (the mean score of the moderator +1 SD). Bodner's (2017) formula was used to calculate effect size across moderator values. All predictors and moderators were mean-centered for more meaningful interpretation of moderating effect (Hayes, 2018).

\section{Results}

\section{Preliminary Analyses}

Descriptive characteristics are found in Table 1. Male and female participants reported similar mean scores on all measurements, except the SABRA-A ${ }^{2}$. Female participants reported experiencing significantly higher levels of racism $(M=29.10, S D=6.25)$ than their male counterparts $(M=26.75$, $S D=7.59)$, with a small effect size $(d=0.34$; Cohen, 1998). Participants who had sought mental health services since COVID-19 reported significantly higher resilience scores $(M=138.78, S D=20.59)$, experiences of subtle and blatant racism $(M=29.99, S D=6.38)$, coping strategy $(M=84.34, S D=12.61)$, and stress-related growth $(M=81.13, S D=14.25)$ than participants who either did not seek professional mental health services or who considered seeking services, but had not used them.

\section{Correlations}

Correlational analyses among all study variables were conducted. Table 1 presents the correlations among the predictive and outcome variables assessed in the study as well as the mean and standard deviations for each variable and internal reliability for each measurement. As expected, ethnic identity, resilience, coping strategy, and stress-related growth were positively and moderately correlated with each other. Interestingly, subtle and blatant racism were also positively related to ethic identity, resilience, coping, and stress-related growth. 


\section{Hierarchical Regression Analyses}

Results from the hierarchical regression analyses are provided in Table 2. The control variables of gender, age, education status, sexual identity, and help-seeking experience were examined in Model 1. Among the control variables, education status, sexual identity, and help-seeking experiences were significantly associated with stress-related growth for Asians and AAPIs. Specifically, participants who had earned a master's degree or higher and identified as heterosexual had significantly lower scores of stress-related growth compared to those who did not identify as heterosexual. Moreover, participants who sought mental health services following the COVID-19 outbreak reported significantly higher scores of overall stress-related growth compared to those who did not use professional mental health services. Model 1 accounted for $11.6 \%$ of the variance in stress-related growth.

The direct effects of subtle and blatant racism on stress-related growth were examined in Model 2. Subtle and blatant racism had a significantly positive relationship with stress-related growth among Asians and AAPIs $(\beta=.456, p<.001)$ after controlling for gender, age, education, sexual identity, and help-seeking experience. Thus, higher levels of subtle and blatant racism were correlated with higher levels of stress-related growth. Among the control variables, only education status was found to be significantly associated with stress-related growth. Model 2 explained $28.8 \%$ of the variance in stress-related growth. The addition of subtle and blatant racism accounted for a $17.2 \%$ increase in the explained variance in stress-related growth, which was deemed a medium effect size (Cohen, 1998).

Ethnic identity was added in Model 3. Results indicated that ethnic identity was significantly positively associated with stress-related growth for Asians and AAPIs $(\beta=.244, p<.001)$ after controlling for gender, age, education, sexual identity, and help-seeking experience. Based on these results, participants in the study who endorsed stronger levels of ethnic identity were more likely to cultivate higher levels of stressrelated growth. Model 3 accounted for 33.5\% of the variance in stress-related growth. The addition of ethnic identity explained $4.7 \%$ of increase in the variance of stress-related growth.

Resilience and coping strategy were added and analyzed in Model 4. Both resilience and coping strategy had significantly positive associations with stress-related growth for Asians and AAPIs after controlling for gender, age, education, sexual identity, and help-seeking experience. Specifically, Asians and AAPIs who had higher levels of resilience and higher levels of coping strategy were more likely to develop higher levels of stress-related growth. Model 4 explained $66.2 \%$ of the variance in stress-related growth. The addition of resilience and coping strategy accounted for a 32.7\% increase in the explained variance in stress-related growth, which represented a large effect size (Cohen, 1998).

\section{Moderating Effect of Resilience and Coping Strategy}

To examine the moderating effect of resilience and coping strategy, Hayes' (2018) PROCESS macro (Model 1) was employed using 10,000 bootstrapping resamples. As shown in Table 3, coping strategy was significantly positively related to the slope of subtle and blatant racism on stress-related growth $(\beta=.017, p<.001)$. Based on these results, coping strategy significantly moderated (i.e., strengthened) the positive link between racism and stress-related growth. As the moderator, coping strategy explained $1.4 \%$ of the total variance $(51.2 \%)$ in stress-related growth, yielding a small effect size (Cohen, 1998). The nature of the moderating effect is presented in the simple slope analyses (Figure 1). Subtle and blatant racism had a significant effect on the development of stress-related growth for Asians and AAPIs with higher levels of coping strategy $(+1 \mathrm{SD} ; b=.468,95 \% \mathrm{CI}[.169, .767])$, but the significant effect did not hold for those with lower levels of coping strategy (-1 SD; $b=.017,95 \%$ CI $[-.224, .257])$. A +2 SD increase in resilience yielded less than .001 change in the conditional effect on stress-related growth, which was small in magnitude (Bodner, 2017). Thus, resilience did not significantly moderate the link between racism and stress-related growth. 


\section{Table 2}

Results From Hierarchical Multiple Regression and Moderated Path Analysis

\begin{tabular}{|c|c|c|c|c|c|c|c|c|}
\hline \multirow[b]{2}{*}{ Variables } & \multicolumn{2}{|c|}{ Model 1} & \multicolumn{2}{|c|}{ Model 2} & \multicolumn{2}{|c|}{ Model 3} & \multicolumn{2}{|c|}{ Model 4} \\
\hline & $B$ (S.E.) & $\beta$ & $B$ (S.E.) & $\beta$ & $B$ (S.E.) & $\beta$ & $B$ (S.E.) & $\beta$ \\
\hline \multicolumn{9}{|l|}{ Gender } \\
\hline Male & $\begin{array}{l}-1.668 \\
(1.718)\end{array}$ & -.051 & $\begin{array}{c}.187 \\
(1.559)\end{array}$ & .006 & $\begin{array}{c}-.036 \\
(1.510)\end{array}$ & -.001 & $\begin{array}{l}-1.831 \\
(1.085)\end{array}$ & -.056 \\
\hline \multicolumn{9}{|l|}{$\begin{array}{l}\text { Age } \\
>34 \text { (ref) }\end{array}$} \\
\hline$\leq 34$ & $\begin{array}{l}-1.205 \\
(1.623)\end{array}$ & -.039 & $\begin{array}{l}-2.059 \\
(1.462)\end{array}$ & -.067 & $\begin{array}{l}-2.287 \\
(1.417)\end{array}$ & -.074 & $\begin{array}{c}.397 \\
(1.027)\end{array}$ & .013 \\
\hline \multicolumn{9}{|l|}{$\begin{array}{l}\text { Education } \\
\leq \text { Bachelor (ref) }\end{array}$} \\
\hline$\geq$ Master & $\begin{array}{l}-5.017 \\
(1.698)\end{array}$ & $-.157^{* *}$ & $\begin{array}{l}-3.470 \\
(1.537)\end{array}$ & $-.109^{*}$ & $\begin{array}{l}-2.249 \\
(1.510)\end{array}$ & -.070 & $\begin{array}{c}.320 \\
(1.090)\end{array}$ & .010 \\
\hline \multicolumn{9}{|l|}{$\begin{array}{l}\text { Sexual Identity } \\
\text { Non-hetero (ref) }\end{array}$} \\
\hline Heterosexuality & $\begin{array}{l}-4.479 \\
(1.697)\end{array}$ & $-.139 * *$ & $\begin{array}{l}-1.721 \\
(1.557)\end{array}$ & -.109 & $\begin{array}{l}-1.621 \\
(1.508)\end{array}$ & -.050 & $\begin{array}{l}-1.512 \\
(1.090)\end{array}$ & -.047 \\
\hline \multicolumn{9}{|l|}{$\begin{array}{l}\text { Help-Seeking } \\
\text { No (ref) }\end{array}$} \\
\hline Yes & $\begin{array}{c}6.796 \\
(1.605)\end{array}$ & $.225^{* * *}$ & $\begin{array}{c}2.691 \\
(1.517)\end{array}$ & .089 & $\begin{array}{c}2.880 \\
(1.469)\end{array}$ & .095 & $\begin{array}{c}.452 \\
(1.065)\end{array}$ & .015 \\
\hline SBRS & & & $\begin{array}{l}.947 \\
(.108)\end{array}$ & $.456^{* * *}$ & $\begin{array}{c}.734 \\
(.114)\end{array}$ & $.354^{* * *}$ & $\begin{array}{l}.220 \\
(.095)\end{array}$ & $.106^{*}$ \\
\hline MEIM & & & & & $\begin{array}{l}1.152 \\
(.243)\end{array}$ & $.244^{* * *}$ & $\begin{array}{l}-.172 \\
(.190)\end{array}$ & -.037 \\
\hline Resilience & & & & & & & $\begin{array}{l}.357 \\
(.029)\end{array}$ & $.496^{* * *}$ \\
\hline Coping & & & & & & & $\begin{array}{l}.433 \\
(.059)\end{array}$ & $.375^{* * *}$ \\
\hline $\mathrm{R}^{2}$ & & & & & & 35 & & 62 \\
\hline$\Delta \mathrm{R}^{2}$ & & & & & & 47 & & 27 \\
\hline
\end{tabular}

Note. $B=$ unstandardized regression coefficients; S.E. = standard errors; $\beta=$ standardized coefficients; SBRS = Subtle and Blatant Racism Scale; MEIM = Multigroup Ethnic Identity Measure; ref = reference group.

${ }^{*} p<.05 .{ }^{* *} p<.01 .{ }^{* *} p<.001$ 
Table 3

Results From Moderation Path Analysis

\begin{tabular}{lcccc}
\hline \multicolumn{1}{c}{ Variable } & $\beta$ & SE & LLCI & ULCI \\
\hline SBRS & $0.242^{*}$ & 0.115 & 0.015 & 0.469 \\
Coping & $0.718^{* * *}$ & 0.062 & 0.596 & 0.841 \\
SBRS $\times$ Coping & $0.017^{* *}$ & 0.006 & 0.006 & 0.029 \\
Controlled Variables & & & & \\
$\quad$ Age & -1.420 & 1.215 & -3.811 & 0.971 \\
$\quad$ Gender & -0.681 & 1.297 & -3.232 & 1.871 \\
Education & -1.409 & 1.287 & -3.942 & 1.124 \\
Sexual Identity & 0.185 & 1.304 & -2.380 & 2.750 \\
Help-Seeking & 0.070 & 1.282 & -2.452 & 2.592 \\
\hline SBRS & $0.577^{* * *}$ & 0.089 & 0.403 & 0.751 \\
Resilience & $0.443^{* * *}$ & 0.029 & 0.387 & 0.499 \\
SBRS $\times$ Resilience & 0.001 & 0.004 & -0.006 & 0.009 \\
Controlled Variables & & & & \\
Age & 0.472 & 1.109 & -1.709 & 2.654 \\
Gender & -1.704 & 1.175 & -4.015 & 0.607 \\
Education & -0.084 & 1.174 & -2.227 & 2.395 \\
Sexual Identity & $-2.569^{*}$ & 1.184 & -4.899 & -0.239 \\
Help-Seeking & 1.542 & 1.138 & -0.696 & 3.781 \\
\hline
\end{tabular}

Note. SBRS = Subtle and Blatant Racism Scale; LLCI = lower limit of confidence interval; ULCI = upper limit of confidence interval.

${ }^{*} p<.05 .{ }^{* *} p<.01 .{ }^{* * *} p<.001$.

\section{Supplementary Analyses}

Because the 14 coping subscales demonstrated poor reliability, we examined which types of coping strategies moderated the link between racism and stress-related growth. Among the different types of coping responses, self-blame, religion, humor, venting, substance use, denial, and behavioral disengagement had significant moderation effects on the relation between racism and stress-related growth. On the contrary, self-distraction, active coping, use of emotional support, use of instrumental support, positive reframing, planning, and acceptance did not significantly moderate the relationship between racism and stress-related growth. 


\section{Figure 1}

Coping Strategy Moderates the Effect of Subtle and Blatant Racism on Stress-Related Growth

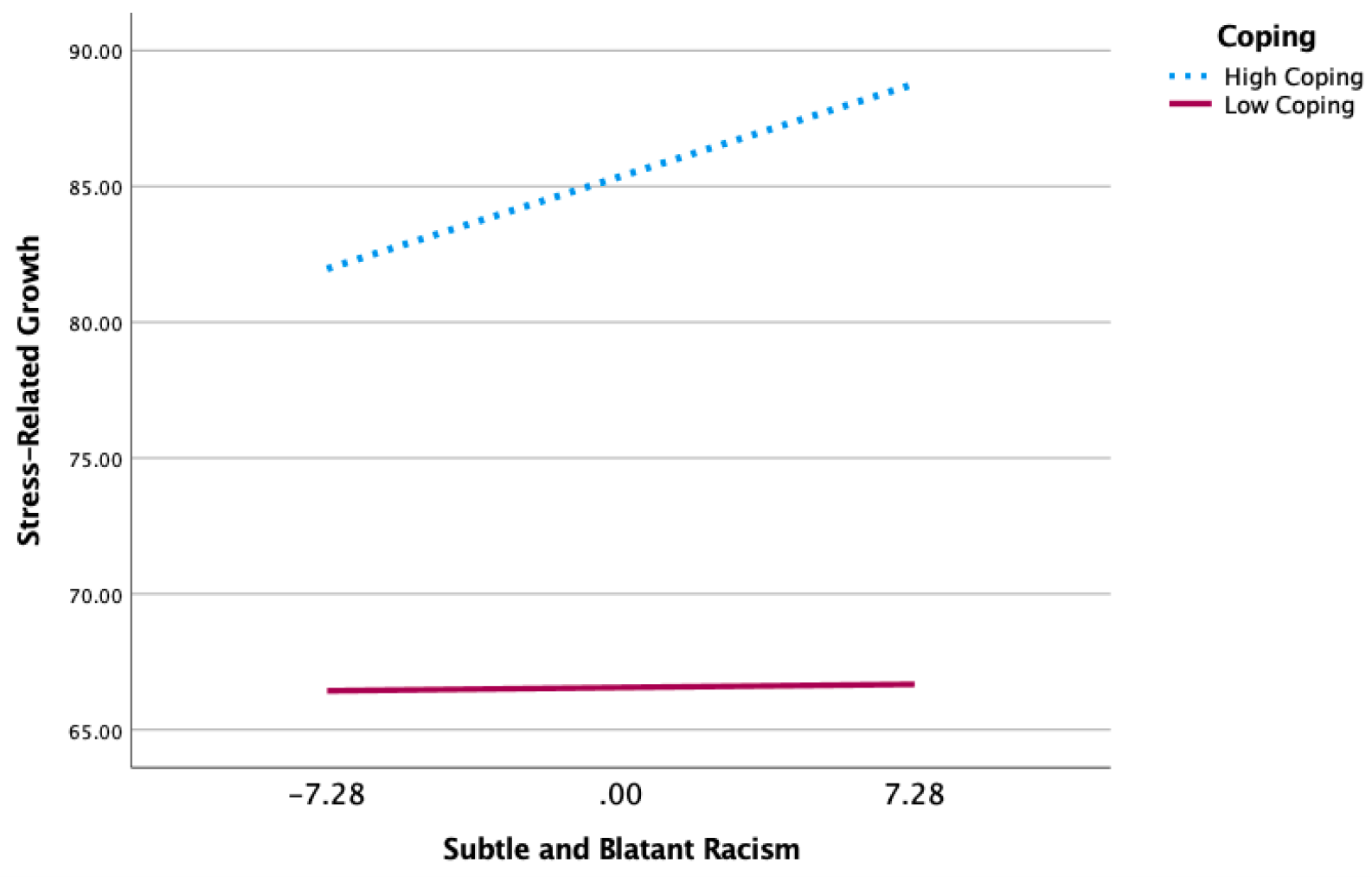

\section{Discussion}

The present study examined the extent to which coping, resilience, experiences of racism, and ethnic identity predicted stress-related growth in a national convenience sample of Asian and AAPI individuals. The results of our exploratory study provide empirical evidence for the moderating effects of coping on the relationship between racial discrimination and stress-related growth in Asians and AAPIs following the COVID-19 pandemic. In our study, ethnic identity was positively associated with stress-related growth, which further supports the current body of research linking ethnic identity to well-being (Iwamoto \& Liu, 2010; Mossakowski, 2003; Yip et al., 2019). Our findings may be additionally explained through the lens of social identity theory (Tajfel \& Turner, 1979), which posits that individuals who strongly identify with their social identities (i.e., ethnic and/or racial identities) are better equipped to leverage effective coping strategies that protect their overall self-concept and buffer the harmful impact of discrimination.

Participants in the study who used mental health services following COVID-19 also reported significantly higher levels of racial discrimination, resilience, coping, and stress-related growth compared to Asians and AAPIs who did not use professional mental health services. The results from our study are consistent with existing research that asserted how individuals may cultivate coping responses following traumatic experiences (Helgeson et al., 2006; Janoff-Bulman, 2004; Tedeschi \& Calhoun, 2004) in ways that can strengthen the relationship between stressful experiences (i.e., racism) and stress-related growth (Park et al., 1996; Tedeschi \& Calhoun, 2004). The results of our study 
therefore contribute to a larger body of research that establishes the relationship between stress-related growth and psychological health, optimism, positive affect, and psychological well-being (Bostock et al., 2009; Bower et al., 2009; Durkin \& Joseph, 2009) while contributing nascent findings to the relationship between COVID-19 racial discrimination and stress-related growth in Asian and AAPI communities.

The results from Model 1 indicated education status, sexual identity, and help-seeking experiences were significantly associated with stress-related growth for Asians and AAPIs in the study. Specifically, participants who reported higher levels of education and identified as heterosexual or straight had lower scores of stress-related growth compared to those who did not identify as heterosexual. These findings are notable as individuals with lesbian, gay, bisexual, and other marginalized identities experience more stress and mental health issues compared to their heterosexual counterparts (Mongelli et al., 2019), resulting in greater opportunities to cultivate coping responses, build resilience, and establish meaningful social supports (Helgeson et al., 2006; Janoff-Bulman, 2004; Tedeschi \& Calhoun, 2004). Participants in our study who used mental health services following the COVID-19 outbreak reported significantly higher levels of stress-related growth compared to Asians and AAPIs who did not use professional mental health services. One possible explanation for this finding may be that participants who sought mental health services already demonstrated higher levels of psychological mindedness, which may have influenced higher levels of stress-related growth following COVID-19-related racial discrimination.

In our study, the combined effects of resilience and coping explained $66.2 \%$ of the variance in Model 4, with coping strategies moderating the relationship between experiences of racism and stress-related growth. Participants in our study may have learned cognitive coping responses in the therapeutic setting that mitigated the effects of racism and cultivated stress-related growth. Our findings are consistent with the results of a meta-analysis $(n=103)$ that identified coping responses such as reappraisal, acceptance, and support seeking as significant predictors of stress-related growth (Prati \& Pietrantoni, 2009). The specific coping responses that moderated the link between racism and stress-related growth in this study were self-blame, religion, humor, venting, substance use, denial, and disengagement. Leveraging these coping strategies in response to stressful experiences may be consistent with culturally congruent coping responses that protect Asians and AAPIs by avoiding the stressor (Edwards \& Romero, 2008; Litam, 2020). Consistent with extant research on culturally congruent coping, engaging in self-blame responses may maintain interpersonal harmony (Wei et al., 2010), and humor, venting, denial, disengagement, and substance use may help one evade problems or adjust one's feelings to the environment (Pokhrel \& Herzog, 2014). The results of our study are thus consistent with research that emphasizes the influence of cultural notions on coping responses (Lazarus \& Folkman, 1984; Tweed \& Conway, 2006) while contributing new findings about which coping responses may contribute to stress-related growth in Asian and AAPI communities following COVID-19.

\section{Implications for Counselors}

This study highlights how experiences of racism, ethnic identity, resilience, and coping strategies may cultivate stress-related growth among Asian and AAPI individuals who experience COVID-19-related racial discrimination. Each of these variables were found to predict stress-related growth in our study. Mental health professionals working with Asian and AAPI clients who have experienced COVID-19 racism are encouraged to consider how their clients' ethnic identity, resilience, and coping strategies may be leveraged to promote their well-being. In this exploratory study, participants with higher levels of ethnic identity experienced greater levels of stress-related growth, so it may behoove mental health professionals to embolden Asian and AAPI clients to fortify the quality of their ethnic group affiliation by pursuing cultural practices that promote a sense of group belongingness (Phinney, 1990). For 
example, ethnic identity can be cultivated by fostering community connection through local Asian and AAPI organizations, embracing cultural notions, and learning more about one's culture, background, and family history (Chan \& Litam, 2021; Litam, 2020). Clients who embody strong ethnic identities may be more likely to employ coping strategies that align with culturally embedded values; therefore, it is essential that mental health counselors recognize their own cultural values while remaining respectful of their client's cultural values (Chang \& O'Hara, 2013; see MSJCC, Ratts et al., 2016).

Given the importance of coping strategies and resilience on stress-related growth, mental health professionals are encouraged to identify and amplify clients' existing coping strategies while fostering responses that cultivate resilience. Though limited, a supplementary analysis indicated that different forms of coping, such as self-blame, religion, humor, venting, substance use, denial, and disengagement, may moderate the relationship between racism and stress-related growth among Asian and AAPI communities facing racial discrimination following COVID-19. Thus, mental health professionals working with Asian and AAPI clients must assess the intention and outcome of client coping responses and challenge individualistic assumptions that minimize the value of culturally congruent coping strategies. The importance of using culturally sensitive therapeutic interventions when supporting Asian and AAPI clients during COVID-19 has been established (Litam, 2020). For example, mental health professionals must challenge assumptions that disengagement coping strategies are inherently problematic for their Asian and AAPI clients (Wong et al., 2010). Instead, mental health professionals are encouraged to focus on the usefulness of their Asian and AAPI clients' coping strategies without imposing their own preconceived notion of what healthy and unhealthy coping entails. Of note, substance use was identified as a coping strategy used by participants in this study. Counselors are therefore called to examine the purpose and outcomes associated with client substance use with nuance to determine the extent to which ongoing substance use may contribute to mental health sequelae.

\section{Limitations and Future Areas of Study}

The results of the study must be interpreted within the context of methodological limitations. First, although all participants resided in the United States, the majority of participants held international statuses compared to U.S. citizens or permanent residents. Readers must be cautioned before generalizing these findings to AAPIs, who may endorse generational differences. Next, it is possible that participants recruited from MTurk may not be representative of the general Asian and AAPI population in the United States (Burnham et al., 2018). Future areas of research may consider incorporating various strategies to recruit more representative samples. Additional areas of investigation may also examine how generational identity may affect the extent to which coping, resilience, racism, and ethnic identity predict stress-related growth. Next, although a significant positive association was found between using professional mental health services and levels of resilience, racism, coping, and stress-related growth, it is unknown whether participants in the study already embodied higher levels of stress-related growth, coping, and resilience before seeking services. Future areas of study may examine whether these variables may actually predict help-seeking behaviors in Asians and AAPIs. For example, seeking professional mental health services is consistent with predictors of stress-related growth, including leveraging community support, engaging in cognitive responses, appraisal, and facilitating meaning making (Park \& Fenster, 2004; Prati \& Pietrantoni, 2009). Moreover, the validity of the findings from the supplementary analysis could be limited because of the low reliability of 14 subscales. Finally, Asians and AAPIs were aggregated in the study, which results in the loss of important within-group distinctions. Future studies are warranted that investigate the extent to which coping, resilience, racism, and ethnic identity predict stress-related growth in specific Asian and AAPI subgroups. 


\section{Conclusion}

Asians and AAPIs who employ culturally congruent coping responses may experience greater levels of stress-related growth following experiences of COVID-19-related racial discrimination. In this study, higher levels of ethnic identity, resilience, and coping responses predicted stress-related growth in a national convenience sample of Asians and AAPIs residing in the United States. Asians and AAPIs in this study who sought professional mental health services reported higher levels of racism and endorsed higher scores of resilience, coping, and stress-related growth compared to those who did not seek professional mental health services. Mental health professionals are encouraged to support Asian and AAPI clients in strengthening their ethnic identity, building resilience, and using culturally congruent coping responses to mitigate the effects of COVID-19-related racism and promote the development of stress-related growth.

\section{Conflict of Interest and Funding Disclosure}

The authors reported no conflict of interest or funding contributions for the development of this manuscript.

\section{References}

Anandavalli, S., Harrichand, J. J. S., \& Litam, S. D. A. (2020). Counseling international students in times of uncertainty: A critical feminist and bioecological approach. The Professional Counselor, 10(3), 365-375. https://doi.org/10.15241/sa.10.3.365

Asmundson, G. J. G., \& Taylor, S. (2020). Coronaphobia: Fear and the 2019-nCoV outbreak. Journal of Anxiety Disorders, 70. https://doi.org/10.1016/j.janxdis.2020.102196

Boals, A., \& Schuler, K. L. (2018). Reducing reports of illusory posttraumatic growth: A revised version of the Stress-Related Growth Scale (SRGS-R). Psychological Trauma: Theory, Research, Practice, and Policy, 10(2), 190-198. https://doi.org/10.1037/tra0000267

Bodner, T. E. (2017). Standardized effect sizes for moderated conditional fixed effects with continuous moderator variables. Frontiers in Psychology, 8, 562. https://doi.org/10.3389/fpsyg.2017.00562

Bostock, L., Sheikh, A. I., \& Barton, S. (2009). Posttraumatic growth and optimism in health-related trauma: A systematic review. Journal of Clinical Psychology in Medical Settings, 16(4), 281-296. https://doi.org/10.1007/s10880-009-9175-6

Bower, J. E., Moskowitz, J. T., \& Epel, E. (2009). Is benefit finding good for your health? Pathways linking positive life changes after stress and physical health outcomes. Current Directions in Psychological Science, 18(6), 337-341. https://doi.org/10.1111/j.1467-8721.2009.01663.x

Brown, S. D., Unger Hu, K. A., Mevi, A. A., Hedderson, M. M., Shan, J., Quesenberry, C. P., \& Ferrara, A. (2014). The Multigroup Ethnic Identity Measure-Revised: Measurement invariance across racial and ethnic groups. Journal of Counseling Psychology, 61(1), 154-161. https://doi.org/10.1037/a0034749

Budiman, A., \& Ruiz, N. G. (2021). Key facts about Asian Americans, a diverse and growing population. Pew Research Center. https://www.pewresearch.org/fact-tank/2017/09/08/key-facts-about-asian-americans

Burnham, M. J., Le, Y. K., \& Piedmont, R. L. (2018). Who is MTurk? Personal characteristics and sample consistency of these online workers. Mental Health, Religion \& Culture, 21(9-10), 934-944. https://doi.org/10.1080/13674676.2018.1486394

Cacioppo, J. T., \& Hawkley, L. C. (2003). Social isolation and health, with an emphasis on underlying mechanisms. Perspectives in Biology and Medicine, 46(3), S39-S52. https://doi.org/10.1353/pbm.2003.0063 
Cacioppo, J. T., Hawkley, L. C., Crawford, L. E., Ernst, J. M., Burleson, M. H., Kowalewski, R. B., Malarkey, W. B., Van Cauter, E., \& Berntson, G. G. (2002). Loneliness and health: Potential mechanisms. Psychosomatic Medicine, 64(3), 407-417. https://doi.org/10.1097/00006842-200205000-00005

Carver, C. S. (1997). You want to measure coping but your protocol's too long: Consider the Brief COPE. International Journal of Behavioral Medicine, 4(1), 92-100. https://doi.org/10.1207/s15327558ijbm0401_6

Chan, C. D., \& Litam, S. D. A. (2021). Mental health equity of Filipino communities in COVID-19: A framework for practice and advocacy. The Professional Counselor, 11(1), 73-85. https://doi.org/10.15241/cdc.11.1.73

Chang, C. Y., \& O'Hara, C. (2013). The initial interview with Asian American clients. Journal of Contemporary Psychotherapy, 43(1), 33-42. https://doi.org/10.1007/s10879-012-9221-9

Cheng, H.-I. (2013). "A wobbly bed still stands on three legs": On Chinese immigrant women's experiences with ethnic community. Women E Language, 36, 7-25.

Choi, Y., Park, M., Noh, S., Lee, J. P., \& Takeuchi, D. (2020). Asian American mental health: Longitudinal trend and explanatory factors among young Filipino- and Korean Americans. SSM - Population Health, 10. https://doi.org/10.1016/j.ssmph.2020.100542

Cohen, J. (1998). Statistical power analysis for the behavioral sciences (2nd ed.). Lawrence Erlbaum.

Congressional Asian Pacific American Caucus. (2020, February 26). As coronavirus fears incite violence, CAPAC members urge colleagues to not stoke xenophobia. https://capac-chu.house.gov/press-release/coronavirus-fearsincite-violence-capac-members-urge-colleagues-not-stoke-xenophobia

Connor, K. M., \& Davidson, J. R. T. (2003). Development of a new resilience scale: The Connor-Davidson Resilience Scale (CD-RISC). Depression and Anxiety, 18(2), 76-82. https://doi.org/10.1002/da.10113

Cordova, M. J., Riba, M. B., \& Spiegel, D. (2017). Post-traumatic stress disorder and cancer. The Lancet Psychiatry, 4(4), 330-338. https://doi.org/10.1016/S2215-0366(17)30014-7

DeVitre, Z., \& Pan, D. (2020). Asian American values and attitudes towards seeking mental health services. Journal of Asia Pacific Counseling, 10(1), 15-26. https://doi.org/10.18401/2020.10.1.2

Durkin, J., \& Joseph, S. (2009). Growth following adversity and its relation with subjective well-being and psychological well-being. Journal of Loss and Trauma, 14(3), 228-234. https://doi.org/10.1080/15325020802540561

Edmondson, D., Chaudoir, S. R., Mills, M. A., Park, C. L., Holub, J., \& Bartkowiak, J. M. (2011). From shattered assumptions to weakened worldviews: Trauma symptoms signal anxiety buffer disruption. Journal of Loss and Trauma, 16(4), 358-385. https://doi.org/10.1080/15325024.2011.572030

Edwards, L. M., \& Romero, A. J. (2008). Coping with discrimination among Mexican descent adolescents. Hispanic Journal of Behavioral Sciences, 30(1), 24-39. https://doi.org/10.1177/0739986307311431

Erikson, E. H. (1968). Identity: Youth and crisis. W. W. Norton.

Frazier, P. A., Tix, A. P., \& Barron, K. E. (2004). Testing moderator and mediator effects in counseling psychology research. Journal of Counseling Psychology, 51(1), 115-134. https://doi.org/10.1037/0022-0167.51.1.115

Gee, G. C., Spencer, M., Chen, J., Yip, T., \& Takeuchi, D. T. (2007). The association between self-reported racial discrimination and 12-month DSM-IV mental disorders among Asian Americans nationwide. Social Science E Medicine, 64(10), 1984-1996. https://doi.org/10.1016/j.socscimed.2007.02.013

Hayes, A. F. (2018). Introduction to mediation, moderation, and conditional process analysis: A regression-based approach (2nd ed.). Guilford.

Helgeson, V. S., Reynolds, K. A., \& Tomich, P. L. (2006). A meta-analytic review of benefit finding and growth. Journal of Consulting and Clinical Psychology, 74(5), 797-816. https://doi.org/10.1037/0022-006X.74.5.797

Hwang, W.-C., \& Goto, S. (2008). The impact of perceived racial discrimination on the mental health of Asian American and Latino college students. Cultural Diversity and Ethnic Minority Psychology, 14(4), 326-335. https://doi.org/10.1037/1099-9809.14.4.326

Inman, A. G., \& Yeh, C. J. (2007). Asian American stress and coping. In F. T. L. Leong, A. G. Inman, A. Ebreo, L. H. Yang, L. Kinoshita, \& M. Fu (Eds.), Handbook of Asian American psychology (2nd ed., pp. 323-340). SAGE.

Iwamoto, D. K., \& Liu, W. M. (2010). The impact of racial identity, ethnic identity, Asian values, and race-related stress on Asian Americans and Asian international college students' psychological well-being. Journal of Counseling Psychology, 57(1), 79-91. https://doi.org/10.1037/a0017393

Janoff-Bulman, R. (2004). Posttraumatic growth: Three explanatory models. Psychological Inquiry, 15(1), 30-34. 
Jeung, R., \& Nham, K. (2020). Incidents of coronavirus-related discrimination. Asian Pacific Policy \& Planning Council. http://www.asianpacificpolicyandplanningcouncil.org/wp-content/uploads/STOP AAPI HATE MONTHLY REPORT 4 23 20.pdf

Kim, J., \& Kim, H. (2013). The experience of acculturative stress-related growth from immigrants' perspectives. International Journal of Qualitative Studies on Health and Well-Being, 8(1).

https://doi.org/10.3402/qhw.v8i0.21355

Lazarus, R. S., \& Folkman, S. (1984). Stress, appraisal, and coping. Springer.

Le, D. L., \& Ahn, S. (2011). Racial discrimination and Asian mental health: A meta-analysis. The Counseling Psychologist, 39(3), 463-489. https://doi.org/10.1177/0011000010381791

Lee, R. M. (2003). Do ethnic identity and other-group orientation protect against discrimination for Asian Americans? Journal of Counseling Psychology, 50(2), 133-141. https://doi.org/10.1037/0022-0167.50.2.133

Lee, R. M. (2005). Resilience against discrimination: Ethnic identity and other-group orientation as protective factors for Korean Americans. Journal of Counseling Psychology, 52(1), 36-44. https://doi.org/10.1037/0022-0167-52.1.36

Lee, R. M., \& Davis, C., III. (2000). Cultural orientation, past multicultural experience, and a sense of belonging on campus for Asian American college students. Journal of College Student Development, 41(1), 110-115.

Lee, R. M., \& Yoo, H. C. (2004). Structure and measurement of ethnic identity for Asian American college students. Journal of Counseling Psychology, 51(2), 263-269. https://doi.org/10.1037/0022-0167.51.2.263

Leong, F., Park, Y. S., \& Kalibatseva, Z. (2013). Disentangling immigrant status in mental health: Psychological protective and risk factors among Latino and Asian American immigrants. American Journal of Orthopsychiatry, 83(2-3), 361-371. http://doi.org/10.1111/ajop.12020

Liang, C. T. H., \& Fassinger, R. E. (2008). The role of collective self-esteem for Asian Americans experiencing racism-related stress: A test of moderator and mediator hypotheses. Cultural Diversity and Ethnic Minority Psychology, 14(1), 19-28. https://doi.org/10.1037/1099-9809.14.1.19

Lieber, E., Chin, D., Nihira, K., \& Mink, I. T. (2001). Holding on and letting go: Identity and acculturation among Chinese immigrants. Cultural Diversity and Ethnic Minority Psychology, 7(3), 247-261. https://doi.org/10.1037/1099-9809.7.3.247

Lim, J., \& Ashing-Giwa, K. T. (2013). Is family functioning and communication associated with health-related quality of life for Chinese- and Korean-American breast cancer survivors? Quality of Life Research, 22, 1319-1329. https://doi.org/10.1007/s11136-012-0247-y

Linley, P. A., \& Joseph, S. (2004). Positive change following trauma and adversity: A review. Journal of Traumatic Stress, 17(1), 11-21. https://doi.org/10.1023/B:JOTS.0000014671.27856.7e

Litam, S. D. A. (2020). "Take your Kung Flu back to Wuhan": Counseling Asians, Asian Americans, and Pacific Islanders with race-based trauma related to COVID-19. The Professional Counselor, 10(2), 144-156. https://doi.org/10.15241/sdal.10.2.144

Litam, S. D. A., \& Hipolito-Delgado, C. P. (2021). When being "essential” illuminates disparities: Counseling clients affected by COVID-19. Journal of Counseling \& Development, 99(1), 3-10. https://doi.org/10.1002/jcad.12349

Litam, S. D. A., \& Oh, S. (in press). Effects of COVID-19 racial discrimination on depression and life satisfaction among young, middle, and older Chinese Americans. Adultspan Journal.

Litam, S. D. A., \& Oh, S. (2020). Ethnic identity and coping strategies as moderators of COVID-19 racial discrimination experiences among Chinese Americans. Counseling Outcome Research and Evaluation. https://doi.org/10.1080/21501378.2020.1814138

Miller, C. T., \& Kaiser, C. R. (2001). A theoretical perspective on coping with stigma. Journal of Social Issues, 57(1), 73-92. https://doi.org/10.1111/0022-4537.00202

Miller, C. T., \& Major, B. (2000). Coping with stigma and prejudice. In T. F. Heatherton, R. E. Kleck, M. R. Hebl, \& J. G. Hull (Eds.), The social psychology of stigma (pp. 243-272). Guilford.

Mongelli, F., Perrone, D., Balducci, J., Sacchetti, A., Ferrari, S., Mattei, G., \& Galeazzi, G. M. (2019). Minority stress and mental health among LGBT populations: An update on the evidence. Minerva Psychiatrica, 60(1), 2750. https://doi.org/10.23736/S0391-1772.18.01995-7

Mossakowski, K. N. (2003). Coping with perceived discrimination: Does ethnic identity protect mental health? Journal of Health and Social Behavior, 44(3), 318-331. https://doi.org/10.2307/1519782 
The Professional Counselor I Volume 11, Issue 2

Nadal, K. L., Wong, Y., Sriken, J., Griffin, K., \& Fujii-Doe, W. (2015). Racial microaggressions and Asian Americans: An exploratory study on within-group differences and mental health. Asian American Journal of Psychology, 6(2), 136-144. https://doi.org/10.1037/a0038058

Noh, S., \& Kaspar, V. (2003). Perceived discrimination and depression: Moderating effects of coping, acculturation, and ethnic support. American Journal of Public Health, 93(2), 232-238. https://doi.org/10.2105/ajph.93.2.232

Nolen-Hoeksema, S., \& Davis, C. G. (2004). Theoretical and methodological issues in the assessment and interpretation of posttraumatic growth. Psychological Inquiry, 15, 60-64.

O'Rourke, N., \& Hatcher, L. (2013). A step-by-step approach to using SAS for factor analysis and structural equation modeling (2nd ed.). SAS Press.

Osborn, J. W. (2013). Best practices in data cleaning: A complete guide to everything you need to do before and after collecting your data. SAGE.

Park, C. L., Cohen, L. H., \& Murch, R. L. (1996). Assessment and prediction of stress-related growth. Journal of Personality, 64(1), 71-105. https://doi.org/10.1111/j.1467-6494.1996.tb00815.x

Park, C. L., \& Fenster, J. R. (2004). Stress-related growth: Predictors of occurrence and correlates with psychological adjustment. Journal of Social and Clinical Psychology, 23(2), 195-215. https://doi.org/10.1521/jscp.23.2.195.31019

Phinney, J. S. (1990). Ethnic identity in adolescents and adults: Review of research. Psychological Bulletin, 108(3), 499-514. https://doi.org/10.1037/0033-2909.108.3.499

Phinney, J. S. (1992). The Multigroup Ethnic Identity Measure: A new scale for use with diverse groups. Journal of Adolescent Research, 7(2), 156-176. https://doi.org/10.1177/074355489272003

Phinney, J. S. (2003). Ethnic identity and acculturation. In K. M. Chun, P. B. Organista, \& G. Marin (Eds.), Acculturation: Advances in theory, measurement, and applied research (pp. 63-82). American Psychological Association.

Pokhrel, P., \& Herzog, T. A. (2014). Historical trauma and substance use among Native Hawaiian college students. American Journal of Health Behavior, 38(3), 420-429. https://doi.org/10.5993/AJHB.38.3.11

Prati, G., \& Pietrantoni, L. (2009). Optimism, social support, and coping strategies as factors contributing to posttraumatic growth: A meta-analysis. Journal of Loss and Trauma, 14(5), 364-388. https://doi.org/10.1080/15325020902724271

Preacher, K. J., Rucker, D. D., \& Hayes, A. F. (2007). Addressing moderated mediation hypothesis: Theory, methods, and prescriptions. Multivariate Behavioral Research, 42(1), 185-227. https://doi.org/10.1080/002731707001341316

Ratts, M. J., Singh, A. A., Nassar-McMillan, S., Butler, S. K., \& McCullough, J. R. (2016). Multicultural and Social Justice Counseling Competencies: Guidelines for the counseling profession. Journal of Multicultural Counseling and Development, 44(1), 28-48. https://doi.org/10.1002/jmcd.12035

Rzeszutek, M., \& Gruszczyńska, E. (2018). Paradoxical effect of social support among people living with HIV: A diary study investigating the buffering hypothesis. Journal of Psychosomatic Research, 109, $25-31$. https://doi.org/10.1016/j.jpsychores.2018.03.006

Sue, D. W., Sue, D., Neville, H. A., \& Smith, L. (2019). Counseling the culturally diverse: Theory and practice (8th ed.). Wiley.

Tabachnick, B. G., \& Fidell, L. S. (2019). Using multivariate statistics (7th ed.). Pearson.

Tajfel, H., \& Turner, J. C. (1979). An integrative theory of intergroup conflict. In W. G. Austin \& S. Worchel (Eds.), The social psychology of intergroup relations. Brooks Cole.

Tedeschi, R. G., \& Calhoun, L. G. (1995). Trauma and transformation: Growing in the aftermath of suffering. SAGE.

Tedeschi, R. G., \& Calhoun, L. G. (1996). The posttraumatic growth inventory: Measuring the positive legacy of trauma. Journal of Traumatic Stress, 9(3), 455-471. https://doi.org/10.1007/BF02103658

Tedeschi, R. G., \& Calhoun, L. G. (2004). Posttraumatic growth: Conceptual foundation and empirical evidence. Psychological Inquiry, 15(1), 1-18. https://doi.org/10.1207/s15327965pli1501_01

Turner, J. C., Hogg, M. A., Oakes, P. J., Reicher, S. D., \& Wetherell, M. S. (1987). Rediscovering the social group: A selfcategorization theory. Basil Blackwell.

Tweed, R. G., \& Conway, L. G., III. (2006). Coping strategies and culturally influenced beliefs about the world. In P. T. P. Wong \& L. C. J. Wong (Eds.), Handbook of multicultural perspectives on stress and coping (pp. 133153). Springer. 
Vasquez, C., Valiente, C., García, F. E., Contreras, A., Peinado, V., Trucharte, A., \& Bentall, R. P. (2021). Post-traumatic growth and stress-related responses during the COVID-19 pandemic in a national representative simple: The role of positive core beliefs about the world and others. Journal of Happiness Studies. https://doi.org/10.1007/s10902-020-00352-3

Wagnild, G. M., \& Young, H. M. (1993). Development and psychometric evaluation of the Resilience Scale. Journal of Nursing Measurement, 1(2), 165-178.

Wei, M., Heppner, P. P., Ku, T.-Y., \& Liao, K. Y.-H. (2010). Racial discrimination stress, coping, and depressive symptoms among Asian Americans: A moderation analysis. Asian American Journal of Psychology, 1(2), 136-150. https://doi.org/10.1037/a0020157

Wei, M., Wang, K. T., Heppner, P. P., \& Du, Y. (2012). Ethnic and mainstream social connectedness, perceived racial discrimination, and posttraumatic stress symptoms. Journal of Counseling Psychology, 59(3), 486-493. https://doi.org/10.1037/a0028000

Wen, J., Aston, J., Liu, X., \& Ying, T. (2020). Effects of misleading media coverage on public health crisis: A case of the 2019 novel coronavirus outbreak in China. An International Journal of Tourism and Hospitality Research, 31(2), 331-336. https://doi.org/10.1080/13032917.2020.1730621

Wong, G., Derthick, A. O., David, E. J. R., Saw, A., \& Okazaki, S. (2014). The what, the why, and the how: A review of racial microaggressions research in psychology. Race and Social Problems, 6, 181-200. https://doi.org/10.1007/s12552-013-9107-9

Wong, Y. J., Kim, S.-H., \& Tran, K. K. (2010). Asian Americans' adherence to Asian values, attributions about depression, and coping strategies. Cultural Diversity and Ethnic Minority Psychology, 16(1), 1-8. https://doi.org/10.1037/a0015045

Yang, A. (2014). Themes in the career development of 1.5-generation Hmong American women. Journal of Career Development, 41(5), 402-425. https://doi.org/10.1177/0894845313507775

Yeh, C. J., Arora, A. K., \& Wu, K. A. (2006). A new theoretical model of collectivistic coping. In P. T. P. Wong \& L. C. J. Wong (Eds.), Handbook of multicultural perspectives on stress and coping: International and cultural psychology series (pp. 55-72). Springer.

Yip, T., \& Fuligni, A. J. (2002). Daily variation in ethnic identity, ethnic behaviors, and psychological well-being among American adolescents of Chinese descent. Child Development, 73(5), 1557-1572. https://doi.org/10.1111/1467-8624.00490

Yip, T., Wang, Y., Mootoo, C., \& Mirpuri, S. (2019). Moderating the association between discrimination and adjustment: A meta-analysis of ethnic/racial identity. Developmental Psychology, 55(6), 1274-1298. https://doi.org/10.1037/dev0000708

Yoo, H. C., Steger, M. F., \& Lee, R. M. (2010). Validation of the Subtle and Blatant Racism Scale for Asian American College Students (SABRA-A 2). Cultural Diversity and Ethnic Minority Psychology, 16(3), 323-334. https://doi.org/10.1037/a0018674 